From the Hematology Department, Reina Sofia Hospital, Cordoba; Hematology Department, Carlos Haya Hospital, Malaga; and Hematology Department, Cellular Therapy Area, Clinica Universitaria/School of Medicine, Foundation for Applied Medical Research, University of Navarra, Pamplona, Spain.

Submitted February 5, 2005; accepted June 6, 2005

Supported by Grants No. 03/0141, 01/0013-01, 01/F018, and 02/1299 from Fondo de Investigacion Sanitaria (Spain); Navarra Government (grant No. 31/2002): RETIC Grant No. C03/10; Junta de Andalucia Grants No. 03/143 and $03 / 144$, and funds from IMABIS (Malaga, Spain), "UTE project CIMA," Fundación de Investigación Médica Mutua Madrileña Automovilista, and Asociacion Medicina e Investigacion.

Authors' disclosures of potential conflicts of interest are found at the end of this article.

Address reprint requests to Jose Roman-Gomez, MD, Hematology Department, Reina Sofia Hospital, Avda, Menendez Pidal s/n, 14004 Cordoba, Spain; e-mail: peperosa@ teleline.es.

(C) 2005 by American Society of Clinical Oncology

$0732-183 \times / 05 / 2328-7043 / \$ 20.00$ DOI: 10.1200/JCO.2005.01.4944

\title{
Lack of CpG Island Methylator Phenotype Defines a Clinical Subtype of T-Cell Acute Lymphoblastic Leukemia Associated With Good Prognosis
}

Jose Roman-Gomez, Antonio Jimenez-Velasco, Xabier Agirre, Felipe Prosper, Anabel Heiniger, and Antonio Torres

$$
\begin{array}{llllllll}
\text { A } & \text { B } & \text { S } & \text { T } & \text { R } & \text { A } & \text { C } & \text { T }
\end{array}
$$

\section{Purpose}

To examine cancer genes undergoing epigenetic inactivation in a set of T-cell acute lymphoblastic leukemias (T-ALLs) to obtain the $\mathrm{CpG}$ island methylator phenotype (CIMP) in the disease and its possible correlation with clinical features and outcome of the patients.

\section{Patients and Methods}

Methylation-specific polymerase chain reaction was used to analyze methylation of the ADAMTS-1, ADAMTS-5, APAF-1, ASPP-1, CDH1, CDH13, DAPK, DIABLO, DKK-3, LATS-1, LATS-2, NES-1, p14, p15, p16, p57, p73, PARK-2, PTEN, sFRP1/2/4/5, SHP-1, SYK, TMS-1, and WIF-1 genes in samples from 50 consecutive T-ALL patients (19 children and 31 adults). Results were compared with results obtained in 286 B-cell acute lymphoblastic leukemias (B-ALLs).

\section{Results}

A total of $88 \%$ of the T-ALL samples had at least one gene methylated. According to the number of methylated genes observed in each individual sample, 12 patients (24\%) were included in the CIMP - group (zero to two methylated genes), and 38 patients (76\%) were included in the CIMP + group ( $>$ two methylated genes). Clinical features and remission rate did not differ significantly among both groups of patients. Estimated disease-free survival (DFS) rate at 12 years and overall survival (OS) rate at 13 years were $100 \%$ and $91 \%$ for the CIMP - group and $20 \%$ and $17 \%$ for the CIMP+ group, respectively $(P=.0006$ and $P=.003$, respectively). Multivariate analysis demonstrated that methylation profile was an independent prognostic factor in predicting DFS $(P=.05)$ and OS $(P=.02)$. A group of five genes (SYK-1, ASPP-1, sFRP-2, sFRP-5, and WIF-1) showed specificity for T-ALL compared with B-ALL.

\section{Conclusion}

Our results suggest that the methylation profile may be a potential new biomarker of risk prediction in T-ALL.

\section{J Clin Oncol 23:7043-7049. (C) 2005 by American Society of Clinical Oncology}

\section{INTRODUCTION}

On the basis of the expression of lineagespecific antigens and the presence of lineage-specific gene rearrangements, acute lymphoblastic leukemia (ALL) cells are known to be derived from either B- or T-cell precursors. ${ }^{1}$ T-lineage ALLs (T-ALLs) are associated with distinctive biologic behavior and clinical features and, historically, have had a worse prognosis when compared with precursor B-lineage ALLs (B-ALLs). Indeed, $20 \%$ to $50 \%$ of patients with T-ALL die from progressive disease. ${ }^{2}$ Although these outcomes constitute a marked improvement relative to 30 years ago, complete remission (CR) rates and overall survival (OS) have improved only slightly over the last decade. ${ }^{2}$ 
The development of reliable laboratory tests that predict patient prognosis may lead to enhanced patient survival. In B-ALL, malignant cells often have additional specific genetic abnormalities, which have a significant impact on the clinical course of the disease. In contrast, few molecular abnormalities have been detected in T-ALL, and no cytogenetically defined prognostic subgroups have been identified. Moreover, compared with patients with B-ALL, the clinically important features of age at diagnosis, WBC count, and degree of bulky, lymphomatous disease are much less efficient predictors of outcome for patients with T-ALL when treated with modern aggressive chemotherapy. ${ }^{3,4}$ Therefore, useful molecular markers for risk-specific adjustments in therapeutic intensity are necessary in this disease.

DNA methylation is an essential mechanism for the regulation of gene expression in mammalian cells. ${ }^{5}$ Methylation occurs at cytosine residues within $\mathrm{CpG}$ dinucleotides, and many genes are enriched with these dinucleotides in their promoters. These regions are known as $\mathrm{CpG}$ islands and are generally nonmethylated, a condition that allows genes to be transcriptionally competent. Methylation of $\mathrm{CpG}$ islands within gene promoters leads to transcriptional silencing through recruitment of methyl-CpG-binding protein and histone deacetylases. ${ }^{6,7}$ Hence, identification of the methylation patterns of $\mathrm{CpG}$ islands in mammalian cells is important for understanding normal and pathologic gene expression. Several reports have shown that abnormal hypermethylation of $\mathrm{CpG}$ islands may contribute significantly to the pathogenesis of human leukemias, providing an alternative route to gene mutation of cancer-related genes. We have recently shown that the methylation of cytosine nucleotides in ALL cells can help to inactivate tumorsuppressive apoptotic or growth-arresting responses and has prognostic impact in B-ALL. ${ }^{8}$ The presence in individual tumors of multiple genes simultaneously methylated (a condition termed $\mathrm{CpG}$ island methylator phenotype $[\mathrm{CIMP}]+)$ is an independent factor of poor prognosis in both childhood and adult B-ALL in terms of disease-free survival (DFS) and OS. Moreover, methylation status was able to redefine the prognosis of selected B-ALL groups with well-established prognostic features. Lack of CIMP (CIMP-) improved the general poor outcome of patients presenting with the Philadelphia chromosome or high WBC count at diagnosis, whereas presence of methylation worsened the general good outcome of TEL-AML1-positive patients. To determine whether methylation profiles are also of clinical relevance in T-ALL, we have examined multiple key cancer genes undergoing epigenetic inactivation in a set of de novo T-ALLs with the aim of obtaining a map of this alteration in the disease and its possible correlation with clinical features and outcome of the patients.

\section{PATIENTS AND METHODS}

\section{Patients}

We studied 50 consecutive patients ( 37 males and 13 females) with de novo T-ALL who were enrolled onto successive multicenter studies of the "Programa para el Estudio y Tratamiento de las Hemopatias Malignas” (PETHEMA) Spanish study group. All of these patients were referred to the Reina Sofia Hospital of Cordoba, Spain, from January 1990 to December 2003. The median age at diagnosis in the study population as a whole was 21 years (range, 3 to 56 years). Of these patients, 19 were children (median age, 9 years; range, 3 to 14 years), and 31 were adults (median age, 28 years; range, 15 to 56 years). The study was approved by the investigational review boards in accordance with the policies of the Department of Health and Human Services. Informed consent was obtained from the patient or the patient's guardians. Diagnosis was established according to standard morphologic, cytochemical, and immunophenotypic criteria. Immunophenotypic analysis was performed using monoclonal antibodies specific for the following antigens: TdT, HLA-DR, CD7, CD19, CD22, CD10, CD14, CD33, CD13, CD61, CD34, CD2, myeloperoxidase, and surface CD3. For further characterization, expression of the following panel of T-cell-associated antigens was used to establish the degree of differentiation of leukemic blasts: cytoplasmic CD3, CD5, CD1a, CD4, and CD8; samples were classified according to the criteria of the European Group of Immunological Characterization of Leukemia. ${ }^{9}$ After diagnosis, patients were entered onto ALL protocols for high-risk patients of the PETHEMA Spanish study group. The specific PETHEMA ALL treatment protocols in which these patients entered included ALL-89 (between 1990 and 1992; n = 8) and ALL-93 (between 1993 and 2003; $n=42)$. The design and results of these studies have been previously reported. ${ }^{10-13}$ Twenty-seven patients relapsed. Fifteen patients received stem-cell transplantation (five autologous and 10 allogeneic) in the first $(\mathrm{n}=5)$ or second $(\mathrm{n}=10)$ CR. There are 21 patients currently alive. Clinical characteristics of the patients are listed in Table 1. In addition, we also studied 286 consecutive B-ALL patients diagnosed during the same period of time to compare the methylation profiles of both T- and B-ALL.

\section{Gene Selection}

Bone marrow specimen was obtained from all the patients at the moment of diagnosis. High molecular weight DNA was prepared from mononuclear diagnostic marrow cells using conventional methods, frozen at $-80^{\circ} \mathrm{C}$, and retrospectively analyzed to assess the role of methylation profile. In all the cases, the diagnostic bone marrow sample contained blast cells in the ratio of at least $70 \%$. We studied 27 genes belonging to all of the following molecular pathways involved in cell immortalization and transformation: cell cycle $(p 15, p 16, p 57$, and LATS-2), cell adherence and metastasis process (CDH1, CDH13, ADAMTS1, and ADAMTS5), p53 network ( $p 14, p 73$, and ASPP-1), apoptosis (TMS1, APAF-1, $D A P K$, and $D I A B L O)$, inhibitors of the oncogenic WNT signaling pathway (DKK-3, WIF-1, sFRP-1, sFRP-2, sFRP-4, and sFRP-5), differentiation regulation (NES-1), ubiquitination (PARK-2), tyrosine kinase with an essential role in signal transduction $(S Y K)$, negative regulator of the Jak/STAT signaling pathway (SHP-1), and main tumor-suppressor genes (LATS-1 and PTEN; Table 2). Different criteria were used for gene selection. $C D H 1, p 73, p 16$, p15, p57, NES-1, DKK-3, CDH13, p14, TMS1, APAF-1, DAPK, PARKIN, LATS-1, and PTEN were selected because of their frequent methylation in ALL. ${ }^{8}$ The other genes were studied 


\begin{tabular}{|c|c|c|c|}
\hline \multirow[b]{2}{*}{ Characteristic } & \multicolumn{2}{|c|}{$\%$ of Patients } & \multirow[b]{2}{*}{$P$} \\
\hline & $\begin{array}{l}\text { CIMP- } \\
(\mathrm{n}=12)\end{array}$ & $\begin{array}{c}\text { CIMP+ } \\
(\mathrm{n}=38)\end{array}$ & \\
\hline \multicolumn{3}{|l|}{ Age } & \multirow[t]{3}{*}{ NS } \\
\hline Younger than 15 years & 25 & 75 & \\
\hline Older than 15 years & 20 & 80 & \\
\hline \multicolumn{3}{|l|}{ Sex } & \multirow[t]{3}{*}{ NS } \\
\hline Male & 64 & 72 & \\
\hline Female & 36 & 28 & \\
\hline \multicolumn{3}{|l|}{ WBC count } & \multirow[t]{3}{*}{ NS } \\
\hline$<50 \times 10^{9} / \mathrm{L}$ & 40 & 42 & \\
\hline$>50 \times 10^{9} / \mathrm{L}$ & 60 & 58 & \\
\hline \multicolumn{3}{|l|}{ Immunophenotype } & \multirow[t]{6}{*}{ NS } \\
\hline $\mathrm{T} 1$ & 0 & 6 & \\
\hline T2 & 50 & 53 & \\
\hline Т3 & 25 & 30 & \\
\hline T4 & 10 & 5 & \\
\hline Incomplete & 15 & 6 & \\
\hline BMT & 25 & 31 & NS \\
\hline \multicolumn{3}{|l|}{ Treatment } & \multirow[t]{3}{*}{ NS } \\
\hline PETHEMA 89 & 17 & 16 & \\
\hline PETHEMA 93 & 83 & 84 & \\
\hline Best response, CR & 91 & 88 & NS \\
\hline \multicolumn{3}{|l|}{ Cytogenetics } & \multirow[t]{7}{*}{ NS } \\
\hline Normal & 40 & 50 & \\
\hline Not assessable & 20 & 20 & \\
\hline $14 q 11$ & 10 & 20 & \\
\hline del (6q) & 10 & 0 & \\
\hline del (7q) & 10 & 0 & \\
\hline Other & 10 & 10 & \\
\hline Relapse & 0 & 68 & $<.0001$ \\
\hline Death & 9 & 70 & $<.0001$ \\
\hline \multicolumn{4}{|c|}{$\begin{array}{l}\text { Abbreviations: T-ALL, T-cell acute lymphoblastic leukemia; CIMP-, } \\
\text { patients with zero to two CpG island methylated genes; CIMP+, patients } \\
\text { with more than two } \mathrm{CpG} \text { island methylated genes; NS, not significant; } \\
\text { BMT, bone marrow transplantation; PETHEMA, Programa para el Estudio } \\
\text { y Tratamiento de las Hemopatias Malignas; CR, complete remission. }\end{array}$} \\
\hline
\end{tabular}

because they have been found to be methylated in other malignancies, including leukemic cell lines, and their abnormal expression could have potentially important roles in ALL. ${ }^{14-21}$ The regions where these genes reside are not prone to mutations, deletions, or rearrangement in the majority of human leukemias; however, microsatellite markers from these regions have shown that most of them are common sites for loss of heterozygocity in ALL. ${ }^{23}$ Each of these genes possesses a $\mathrm{CpG}$ island in the $5^{\prime}$ region, which is normally unmethylated in corresponding normal tissues as expected for a typical CpG island. We and others have shown in previous studies for such genes in individual tumor types that, when these $\mathrm{CpG}$ islands are hypermethylated in cancer cells, expression of the corresponding gene is silenced and the silencing can be partially relieved by demethylation of the promoter region. ${ }^{8,14-21}$ For all these genes, we have analyzed at least 10 normal marrow and peripheral-blood specimens, none of which showed significant methylation.

\section{Methylation-Specific Polymerase Chain Reaction}

Aberrant promoter methylation of these genes was determined by method of methylation-specific polymerase chain reac- tion (MSP) as reported by Herman et al. ${ }^{24}$ MSP distinguishes unmethylated alleles of a given gene based on DNA sequence alterations after bisulfite treatment of DNA, which converts unmethylated but not methylated cytosines to uracils. Subsequent polymerase chain reaction using primers specific to sequences corresponding to either methylated or unmethylated DNA sequences was then performed. Primer sequences of each gene for the unmethylated and methylated reactions have been reported elsewhere. ${ }^{8,14-21}$ Hot start polymerase chain reaction was performed for 30 cycles consisting of denaturation at $95^{\circ} \mathrm{C}$ for 1 minute, annealing at $60^{\circ} \mathrm{C}$ for 1 minute, and extension at $72^{\circ} \mathrm{C}$ for 1 minute, followed by a final 7 -minute extension for all primer sets. The products were separated by electrophoresis on $2 \%$ agarose gel. Bone marrow DNA from healthy donors was used as negative control for methylation-specific assays. Human male genomic DNA universally methylated for all genes (Intergen Company, Purchase, NY) was used as a positive control for methylated alleles. Water blanks were included with each assay. The presence of a clearly visible band in the MSP using primers for the methylated alleles was considered as a positive result for methylation. This result was always confirmed by repeat MSP assays after an independently performed bisulfite treatment. In the sporadic cases where only faint bands were observed in both analyses, methylation results were validated by Southern blot and/or sequencing and/or association with lack of expression assessed by reverse transcriptase polymerase chain reaction, as appropriate. The sensitivity of this MSP was established by using totally methylated, positive control DNA serially diluted by normal lymphocyte DNA. MSPs with 1:10, 1:100, and 1:1,000 diluted positive control DNA produced detectable methylated bands (data not shown).

\section{Statistical Analysis}

For statistical purposes, T-ALL patients were classified into two different methylation groups; patients showing methylation at three or more loci were defined as CIMP+, whereas patients in whom methylation was low (occurring at two or fewer loci) were defined as CIMP-. $P$ values for comparisons of continuous variables between groups of patients were two tailed and based on the Wilcoxon rank sum test. $P$ values for dichotomous variables were based on the Fisher's exact test. The remaining $P$ values were based on the Pearson $\chi^{2}$ test. OS was measured from the day of diagnosis until death from any cause and was censored only for patients known to be alive at last contact. DFS was measured from the day that CR was established until either relapse or death without relapse, and it was censored only for patients who were alive without evidence of relapse at the last follow-up. Distributions of OS and DFS curves were estimated by the Kaplan-Meier method, with 95\% CIs calculated by means of Greenwood's formula. Comparisons of OS or DFS between groups were based on the log-rank test. Comparisons adjusted for significant prognostic factors were based on Cox regression models and hazard regression models. All relapse and survival data were updated in December 2004, and all follow-up data were censored at that point.

\section{RESULTS}

\section{Frequency of Methylation in T-ALL}

Gene methylation frequencies varied from $7 \%$ to $59 \%$. The following 22 genes demonstrated a relatively high frequency of aberrant methylation: NES-1 (59\%), ADAMTS5 


\begin{tabular}{|c|c|c|c|}
\hline Gene & Location & Function & Reference for MSP Primers \\
\hline ADAMTS1 & $21 q 21.2$ & Metalloprotease & Dunn et al ${ }^{15}$ \\
\hline ADAMTS5 & $21 \mathrm{q} 21.3$ & Metalloprotease & Dunn et al ${ }^{15}$ \\
\hline$A P A F-1$ & $12 q 23$ & Apoptosis regulation & Roman-Gomez et al ${ }^{8}$ \\
\hline ASPP-1 & $14 q 32-33$ & p53 costimulator; apoptosis regulation & Mori et al ${ }^{16}$ \\
\hline $\mathrm{CDH1}$ & $16 q 22$ & Cell-cell adhesion & Roman-Gomez et al ${ }^{8}$ \\
\hline $\mathrm{CDH} 13$ & $16 q 24$ & Cell-cell adhesion & Roman-Gomez et al ${ }^{22}$ \\
\hline DAPK & $9 q 34$ & Apoptosis regulation & Roman-Gomez et al ${ }^{8}$ \\
\hline$D I A B L O$ & $12 q 24.31$ & Apoptosis regulation & Mizutani et $\mathrm{al}^{17}$ \\
\hline$D K K-3$ & $11 \mathrm{p} 15$ & Wnt signaling pathway antagonist & Roman-Gomez et al ${ }^{8}$ \\
\hline LATS-1 & $6 q 23-25$ & TSG; G2-M cell-cycle control & Roman-Gomez et al ${ }^{8}$ \\
\hline LATS-2 & $13 q 11-12$ & G1-S cell-cycle control & Li et $\mathrm{al}^{14}$ \\
\hline NES-1 & $19 q 13$ & Growth and differentiation control & Roman-Gomez et al ${ }^{8}$ \\
\hline P14 & $9 \mathrm{p} 21$ & Cell-cycle control; apoptosis regulation & Roman-Gomez et al ${ }^{8}$ \\
\hline P15 & $9 \mathrm{p} 21$ & G1-S cell-cycle control & Roman-Gomez et al ${ }^{8}$ \\
\hline P16 & $9 \mathrm{p} 21$ & TSG; G1-S cell-cycle control & Roman-Gomez et al ${ }^{8}$ \\
\hline P57 & $11 \mathrm{p} 15$ & G1-S cell-cycle control & Roman-Gomez et al ${ }^{8}$ \\
\hline P73 & $1 \mathrm{p} 36$ & G1-S cell-cycle control & Roman-Gomez et al ${ }^{8}$ \\
\hline PARK-2 & $6 q 25-27$ & Ubiquitination & Roman-Gomez et al ${ }^{8}$ \\
\hline PTEN & $10 q 23$ & TSG; cell adhesion/motility; apoptosis; angiogenesis; G1 cell-cycle regulation; signal transduction & Roman-Gomez et al ${ }^{8}$ \\
\hline SFRP-1 & $8 p 12-11.1$ & Wnt signaling pathway antagonist & Lee et $\mathrm{al}^{19}$ \\
\hline sFRP-2 & $4 q 31.3$ & Wnt signaling pathway antagonist & Lee et $\mathrm{al}^{19}$ \\
\hline sFRP-4 & $7 \mathrm{p} 14.1$ & Wnt signaling pathway antagonist & Lee et $\mathrm{al}^{19}$ \\
\hline sFRP-5 & $10 q 24.1$ & Wnt signaling pathway antagonist & Lee et $\mathrm{al}^{19}$ \\
\hline SHP-1 & $12 \mathrm{p} 13$ & Jak/STAT signaling pathway inhibitor & Chim et $\mathrm{al}^{21}$ \\
\hline SYK & $9 q 22$ & Signal transduction & Goodman et $\mathrm{al}^{20}$ \\
\hline TMS-1 & $16 p 11-12$ & Apoptosis regulation & Roman-Gomez et al ${ }^{8}$ \\
\hline WIF-1 & $12 q 14.3$ & Wnt signaling pathway antagonist & Mazieres et al ${ }^{18}$ \\
\hline
\end{tabular}

(57\%), WIF-1 (53\%), sFRP-1 (51\%), SYK (49\%), CDH1 (47\%), ADAMTS1 (43\%), CDH13 (43\%), APAF-1 (40\%), DKK-3 (40\%), LATS-1 (40\%), sFRP-5 (40\%), PARK-2 (37\%), ASPP-1 (34\%), sFRP-2 (33\%), DIABLO (32\%), p14 (27\%), p57 (27\%), LATS-2 (26\%), p73 (26\%), PTEN $(20 \%)$, and $s F R P-4(20 \%)$. Five genes ( $p 15, S H P-1, p 16$, TMS-1, and DAPK) showed a low frequency ( $7 \%$ to $18 \%$ ) of methylation (Table 3). No methylated genes were found in six (12\%) of 50 patients, whereas most patients with T-ALL (44 of 50 patients; $88 \%$ ) had methylation of at least one gene (range, one to 18 methylated genes). No patient was found to have methylation of more than 18 genes. According to the number of methylated genes observed in each individual sample, 12 patients (24\%) were included in the CIMPgroup (zero to two methylated genes), and 38 patients (76\%) were included in the CIMP + group ( $>$ two methylated genes). Although the presence of CIMP + phenotype was similarly distributed between children (75\%) and adults $(80 \%)$, significant differences were found in the methylation status of individual genes between both age groups; $p 15(P=.05), p 57(P=.03)$, and PTEN $(P=.05)$ genes were more frequently methylated in adult ALL patients than in childhood ALL patients. Figure 1 illustrates representative examples of the methylation patterns of the most frequently methylated genes.
Comparative analysis of the methylation frequencies between T-ALL and B-ALL classifies the 27 genes examined into two groups. The first group is the group of genes showing significantly higher frequencies of methylation in T-ALL compared with B-ALL (SYK-1, ASPP-1, sFRP-2, $s F R P-5$, and WIF-1; Table 3). The second group is the group of genes demonstrating similar frequency of methylation in both subtypes of ALL (the remaining 22 genes). Furthermore, there was more global methylation in T-ALL than in B-ALL. In fact, $76 \%$ of T-ALL patients were CIMP+ compared with $60 \%$ of B-ALL patients $(P=.03)$.

\section{Clinical Outcome of T-ALL and Methylation Profile}

As shown in Table 1, clinical and laboratory characteristics did not differ significantly between methylation groups. Median age (CIMP-: median, 18 years; range, 3 to 56 years; CIMP+: median, 21 years; range, 3 to 46 years), type of PETHEMA protocol administered, and number of patients who received stem-cell transplantation were similarly distributed among both CIMP groups.

Table 1 also details the relapse history, CR rates, and mortality for patients included in the different methylation groups. CR rates of patients in the CIMP - and CIMP+ groups were $91 \%$ and $88 \%$, respectively, accounting for 


\begin{tabular}{|c|c|c|c|}
\hline Feature & T-ALL (\%) & B-ALL (\%) & $P$ \\
\hline \multicolumn{4}{|l|}{ Methylated genes } \\
\hline ADAMTS1 & 43 & 45 & NS \\
\hline ADAMTS5 & 57 & 54 & NS \\
\hline APAF-1 & 40 & 34 & NS \\
\hline$A S P P-1$ & 34 & 18 & .01 \\
\hline $\mathrm{CDH} 1$ & 47 & 40 & NS \\
\hline $\mathrm{CDH} 13$ & 43 & 40 & NS \\
\hline DAPK & 7 & 12 & NS \\
\hline DIABLO & 32 & 24 & NS \\
\hline$D K K-3$ & 40 & 32 & NS \\
\hline LATS-1 & 40 & 33 & NS \\
\hline LATS-2 & 26 & 29 & NS \\
\hline$N E S-1$ & 59 & 55 & NS \\
\hline P14 & 27 & 19 & NS \\
\hline P15 & 18 & 20 & NS \\
\hline P16 & 15 & 15 & NS \\
\hline P57 & 27 & 18 & NS \\
\hline P73 & 26 & 18 & NS \\
\hline PARK-2 & 37 & 27 & NS \\
\hline PTEN & 20 & 18 & NS \\
\hline$S F R P-1$ & 51 & 45 & NS \\
\hline sFRP-2 & 33 & 8 & .001 \\
\hline sFRP-4 & 20 & 22 & NS \\
\hline sFRP-5 & 40 & 28 & .05 \\
\hline SHP-1 & 17 & 11 & NS \\
\hline SYK & 49 & 8 & $<.0001$ \\
\hline TMS-1 & 11 & 7 & NS \\
\hline$W I F-1$ & 53 & 26 & .005 \\
\hline \multicolumn{4}{|l|}{ Methylation profile } \\
\hline CIMP- patients, overall & 24 & 40 & .03 \\
\hline CIMP- patients, children & 25 & 57 & .005 \\
\hline CIMP- patients, adults & 20 & 31 & .05 \\
\hline
\end{tabular}

$90 \%$ of the overall CR rate. This suggests that methylation profile did not correlate with response to remission induction therapy. However, patients in the CIMP - group had a lower relapse rate than patients in the CIMP + group $(0 \% v$ $68 \%$, respectively; $P<.0001)$. Mortality rate was also lower for the CIMP - group compared with the CIMP+ group (9\% v 70\%, respectively; $P<.0001$ ). Similar results were obtained in the separate analyses of children (relapse rate, $0 \%$ for CIMP - group $v 58 \%$ for CIMP + group, $P=.05$; mortality rate, $20 \%$ for CIMP - group $v 59 \%$ for CIMP + group, $P=.05$ ) and adults (relapse rate, $0 \%$ for CIMPgroup $v 78 \%$ for CIMP + group, $P=.007$; mortality rate, $0 \%$ for CIMP - group $v 83 \%$ for CIMP + group, $P=.004$ ).

We analyzed the DFS among patients who achieved CR according to the methylation profile. Estimated DFS rates at 12 years were $100 \%$ and $20 \%$ for the CIMP - and CIMP+ groups, respectively $(P=.0006$; Fig $2 \mathrm{~A})$. Estimated cumulative incidence of relapse was $0 \%$ for the CIMP - group and $80 \%$ at 50 months for the CIMP+ group $(P<.0001)$.

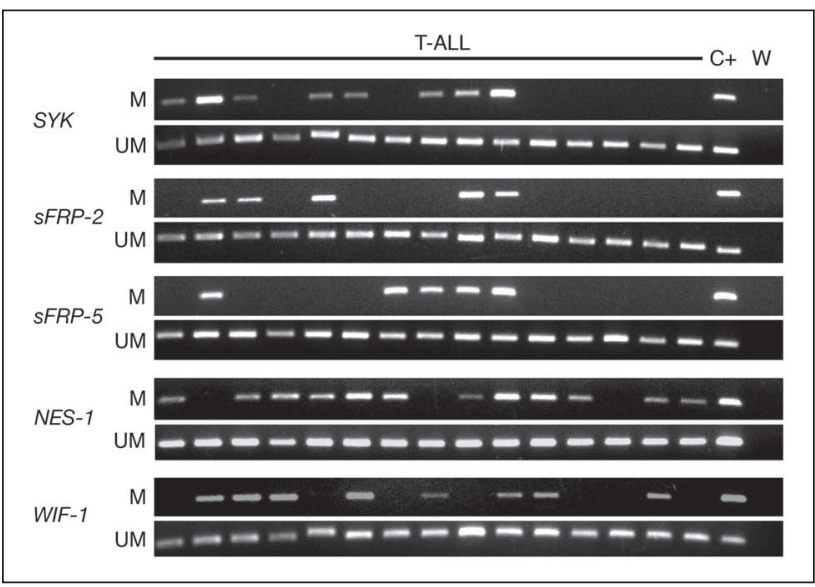

Fig 1. Aberrant promoter methylation of different genes in T-cell acute lymphoblastic leukemia (T-ALL). C+, human male genomic DNA universally methylated for all genes (used as a positive control for methylated alleles); W, blank control without DNA added; UM, unmethylated alleles; M, methylated alleles.

The actuarial OS at 13 years calculated for all leukemic patients was $91 \%$ for CIMP - patients and $17 \%$ for CIMP + patients $(P=.003$; Fig $2 \mathrm{~B})$.

A multivariate analysis of potential prognostic factors demonstrated that hypermethylation profile was the only independent prognostic factor predicting for DFS $(P=.05)$. Methylation status was also independently associated with OS in the global series $(P=.02$; Table 4$)$.

\section{DISCUSSION}

Epigenetic gene silencing is increasingly being recognized as a common way in which cancer cells inactivate cancerrelated genes. ${ }^{5-8}$ In addition to its pathogenic implications, promoter hypermethylation and transcriptional repression of functionally important cancer-related genes may also affect tumor behavior, impacting clinical outcomes. Epigenetic silencing of genes that determine tumor invasiveness, growth patterns, and apoptosis, in particular, may dictate tumor recurrence after treatment and impact OS. Because each tumor may harbor multiple genes susceptible to promoter hypermethylation, individual tumors exhibit different frequencies of hypermethylation profile potentially predictive of a patient's clinical outcome. ${ }^{8,22}$ This methylation profile could be of relevance in those tumors in which clinical and biologic features of prognostic importance are not easily available, as in T-ALL.

Our results indicate that methylation of multiple genes is a common phenomenon in T-ALL and may be the most important way to inactivate cancer-related genes in this disease; $88 \%$ of patients had at least one gene methylated, whereas $76 \%$ of patients had three or more genes methylated. No significant differences were found in the CIMP of 


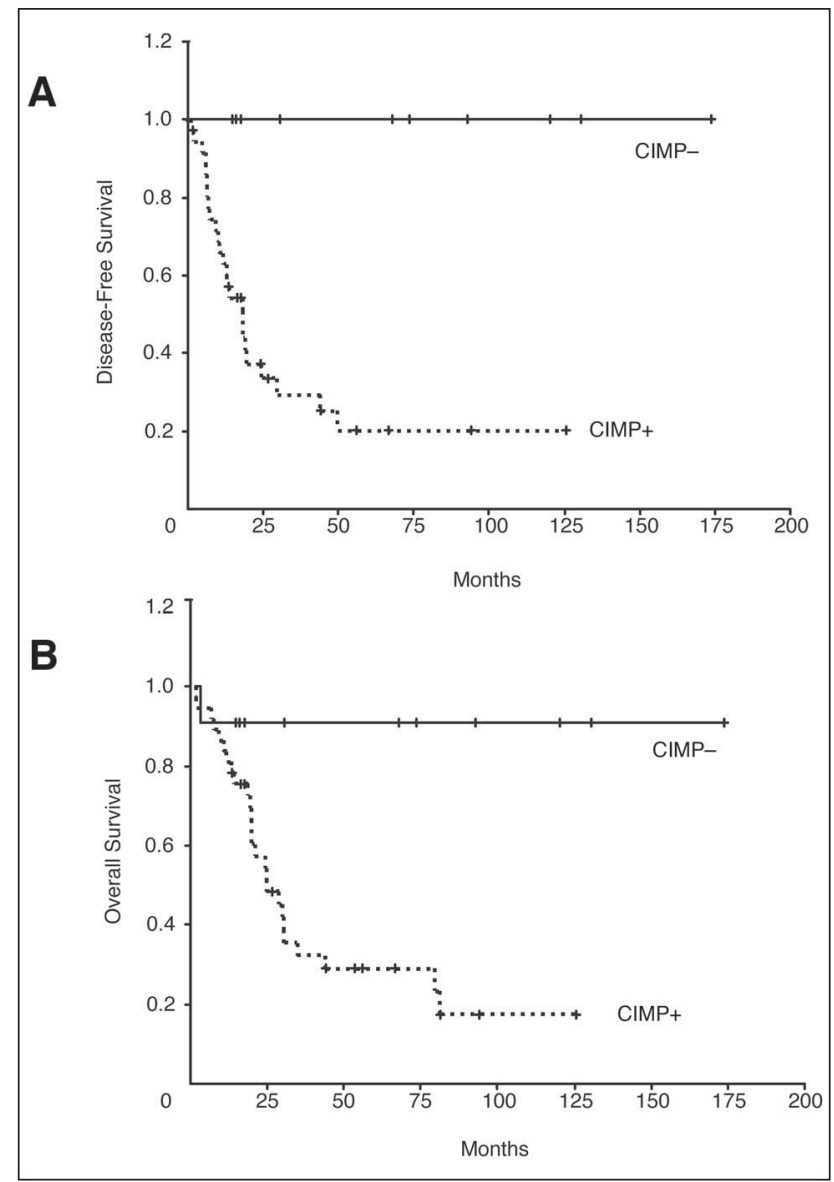

Fig 2. Kaplan-Meier survivor function for T-cell acute lymphoblastic leukemia patients. (A) Disease-free survival (DFS) and (B) overall survival (OS) curves for all the patients enrolled onto the study according to the methylation profile. Log-rank test was highly significant for both DFS $(P=.0006)$ and $\mathrm{OS}(P=.003)$. CIMP, CpG island methylator phenotype; CIMP-, patients with zero to two methylated genes $(n=12) ; C I M P+$, patients with $>2$ methylated genes $(n=38)$.

childhood and adult T-ALLs, suggesting that methylation status in T-ALL is not age related. This is in contrast with the results reported in B-ALL, where adult patients were more frequently CIMP + than children. ${ }^{8}$ This different epigenetic map in both ALL subtypes may have a role in explaining the prognostic importance of age in B-ALL but not in T-ALL. Furthermore, the high frequency of genes simultaneously methylated in T-ALL suggests that CpG island methylation is related to specific methylation defects in subsets of T-ALLs, rather than that methylation of each individual island represents a random event followed by selection for the affected cell.

Our data also show that the methylation in human T-ALL cells can participate in the inactivation of the following three key cellular pathways: (1) growth-deregulating events comprising those that target the principal late-G1 cell-cycle checkpoint either directly ( $p 15, p 16$, and $p 57$ inactivation) or indirectly ( $p 73$, PTEN, NES-1, and LATS-2
Table 4. Multivariate Cox Model for Disease-Free Survival and Overall Survival in T-ALL

\begin{tabular}{lcc}
\hline & Univariate Analysis & $\begin{array}{c}\text { Multivariate Analysis } \\
\text { Feature }\end{array}$ \\
\hline Disease-free survival & & $P$ \\
Methylation profile & .001 & .05 \\
WBC $>50,000 \mu \mathrm{L}$ & .208 & - \\
Age $>15$ years & .460 & - \\
Immunologic subtype & .520 & - \\
Overall survival & & .02 \\
Methylation profile & .006 & .10 \\
WBC $>50,000 \mu \mathrm{L}$ & .04 & - \\
Age $>15$ years & .66 & - \\
Immunologic subtype & .71 & \\
\hline
\end{tabular}

Abbreviation: T-ALL, T-cell acute lymphoblastic leukemia.

inactivation) and those that regulate the G2-M transition downregulating CDC2/cyclin A kinase activity (LATS-1); (2) the apoptotic program through inactivation of $p 14$, TMS1, APAF-1, DIABLO, and DAPK; and (3) the cell-cell adhesion by the inactivation of some members of the cadherin $(C D H 13$ and $C D H 1)$ and metalloprotease (ADAMTS1 and ADAMTS5) families. Because the frequencies of methylation of these genes were similar in T- and B-ALL, one could speculate that the disruption of these oncogenic pathways is a common phenomenon in all types of lymphoid leukemogenesis. However, a group of five genes ( $S Y K-1$, $A S P P-1, s F R P-2, s F R P-5$, and WIF-1) showed specificity for T-ALL, suggesting that they play an important role in T-cell-lineage leukemogenesis.

Patients with T-ALL who experienced relapse had a poor outcome. It would be beneficial to identify high-risk T-cell patients at diagnosis or soon thereafter to modify their initial therapy with the goal of preventing treatment failure. However, conventionally applied epidemiologic features fail to identify these patients. There are no significant differences in event-free survival for T-ALL patients based on age, presenting leukocyte blood cell count, sex, CNS involvement, or presence of a mediastinal mass. ${ }^{1-4}$ Thus, novel prognostic factors need to be identified in patients with T-ALL.

Early response measures may be useful in differentiating good- and poor-risk T-ALL patients. Initial response to prednisone prophase is one such predictor. For example, on a protocol conducted by the Berlin-Frankfurt-Muenster group, the event-free survival of T-ALL patients with a favorable prednisone response (78\%) was superior to the event-free survival of patients with a poor response $(32 \%){ }^{25}$ Levels of minimal residual disease may also provide useful prognostic information. Cave et $\mathrm{al}^{26}$ reported that high levels of minimal residual disease at the end of induction therapy correlated with risk of relapse in T-ALL patients. In addition, expression of oncogenic 
transcription factors, such as HOX $11 / \mathrm{HOX} 11 \mathrm{~L} 2,{ }^{27,28}$ and studies of gene expression profiles may potentially identify biologically distinctive, prognostically significant subsets of patients with T-ALL, as well as potential targets for novel therapies. ${ }^{29}$

Complementing these studies, we have shown that aberrant methylation of $\mathrm{CpG}$ islands is quantitatively different in individual tumors within the same tumor type, and this patient-specific methylation profile provides important prognostic information in T-ALL patients. The presence in individual tumors of multiple epigenetic events that affect each of the pathways discussed earlier is a factor of poor prognosis in T-ALL. Patients with methylation of three or more genes had a poorer DFS and OS than patients with two or less methylated genes. Multivariate analysis confirmed that methylation profile was associated with a shorter DFS and OS. Therefore, methylation profiling in T-ALL could be clinically important for guiding the selection of therapy and also providing a basis for developing novel therapies, such as demethylation treatment. Because the number of samples analyzed in our study was relatively small, our results should be independently confirmed in larger series.

In summary, our results indicate that simultaneously aberrant methylation affecting key molecular pathways is a common phenomenon in T-ALL. The methylation profile seems to be an important factor in predicting the clinical outcome of T-ALL patients.

\section{Authors' Disclosures of Potential Conflicts of Interest}

The authors indicated no potential conflicts of interest.

\section{REFERENCES}

1. Pui $\mathrm{C}-\mathrm{H}$, Evans WE: Acute lymphoblastic leukemia. N Engl J Med 339:605-615, 1998

2. Uckun FM, Sensel MG, Sun L, et al: Biology and treatment of childhood T-lineage acute lymphoblastic leukemia. Blood 91:735-746, 1998

3. Pullen J, Shuster JJ, Link MP, et al: Significance of commonly used prognostic factors differs for children with T-cell acute lymphoblastic leukemia (ALL) as compared to those with B-precursor ALL: A Pediatric Oncology Group study. Leukemia 13:1696-1707, 1999

4. Goldberg JM, Silverman LB, Levy DE, et al: Childhood T-cell acute lymphoblastic leukemia: The Dana-Farber Cancer Institute Acute Lymphoblastic Leukemia Consortium Experience. J Clin Oncol 21:3616-3622, 2003

5. Bird A: DNA methylation patterns and epigenetic memory. Genes Dev 16:6-21, 2002

6. Das PM, Singal R: DNA methylation and cancer. J Clin Oncol 22:4632-4642, 2004

7. Herman JG, Baylin SB: Gene silencing in cancer in association with promoter hypermethylation. N Engl J Med 349:2042-2054, 2003

8. Roman-Gomez J, Jimenez-Velasco A, Castillejo JA, et al: Promoter hypermethylation of cancer-related genes: A strong independent prognostic factor in acute lymphoblastic leukemia. Blood 104:2492-2498, 2004

9. Bene MC, Castoldi G, Knapp W, et al: Proposals for the immunological classification of acute leukemias: European Group for the Immunological Characterization of Leukemias (EGIL). Leukemia 9:1783-1786, 1995

10. Ortega JJ: Spanish acute Iymphoblastic leukemia trials. Int J Pediat Hemat Oncol 5:163176, 1998

11. Ribera JM, Ortega JJ, Oriol A, et al: Prognostic value of karyotypic analysis in children and adults with high-risk acute lymphoblastic leuke- mia included in the PETHEMA ALL-93 trial. Haematologica 87:154-166, 2002

12. Ribera JM, Ortega JJ, Oriol A, et al: Late intensification chemotherapy has not improved the results of intensive chemotherapy in adult acute lymphoblastic leukemia: Results of a prospective multicenter randomized trial (PETHEMA ALL-89). Haematologica 83:222-230, 1998

13. Ortega JJ, Ribera JM, Oriol A, et al: Early and delayed consolidation chemotherapy significantly improves the outcome of children with intermediate-risk acute lymphoblastic leukemia. Final results of the prospective randomized PETHEMA ALL-89 Trial. Haematologica 86:586-595, 2001

14. Li Y, Pei J, Xia H, et al: Lats2, a putative tumor suppressor, inhibits G1/S transition. Oncogene 22:4398-4405, 2003

15. Dunn JR, Panutsopulos D, Shaw MW, et al: METH-2 silencing and promoter hypermethylation in NSCLC. Br J Cancer 91:1149-1154, 2004

16. Mori S, Ito G, Usami N, et al: p53 apoptotic pathway molecules are frequently and simultaneously altered in nonsmall cell lung carcinoma. Cancer 100:1673-1682, 2004

17. Mizutani $Y$, Nakanishi $H$, Yamamoto $K$, et al: Downregulation of Smac/DIABLO expression in renal cell carcinoma and its prognostic significance. J Clin Oncol 23:448-454, 2005

18. Mazieres J, He B, You L, et al: Wnt inhibitory factor-1 is silenced by promoter hypermethylation in human lung cancer. Cancer Res 64: 4717-4720, 2004

19. Lee AY, He B, You L, et al: Expression of the secreted frizzled-related protein gene family is downregulated in human mesothelioma. Oncogene 23:6672-6676, 2004

20. Goodman PA, Burkhardt N, Juran B, et al: Hypermethylation of the spleen tyrosine kinase promoter in T-lineage acute lymphoblastic leukemia. Oncogene 22:2504-2514, 2003

21. Chim CS, Wong AS, Kwong YL: Epigenetic dysregulation of the Jak/STAT pathway by fre- quent aberrant methylation of SHP1 but not SOCS1 in acute leukaemias. Ann Hematol 83 527-532, 2004

22. Roman-Gomez J, Castillejo JA, Jimenez A, et al: Cadherin-13, a mediator of calciumdependent cell-cell adhesion, is silenced by methylation in chronic myeloid leukemia and correlates with pretreatment risk profile and cytogenetic response to interferon-alpha. J Clin Oncol 21:1472-1479, 2003

23. Takeuchi $S$, Bartram CR, Wada M, et al: Allelotype analysis of childhood acute lymphoblastic leukemia. Cancer Res 55:5377-5382, 1995

24. Herman JG, Graff JR, Myohanen S, et al: Methylation-specific PCR: A novel PCR assay for methylation status of $\mathrm{CpG}$ islands. Proc Natl Acad Sci U S A 93:9821-9826, 1996

25. Pieters R, Kasper G, Veerman A, et al: Relation between age, immunophenotype and in vitro drug resistance in 395 children with acute Iymphoblastic leukemia: Implications for treatment of infants. Leukemia 12:1344-1348, 1998

26. Cave $\mathrm{H}$, van der Werff ten Bosch J, Manel $A$, et al: Clinical significance of minimal residual disease in childhood acute lymphoblastic leukemia. N Engl J Med 339:591-598, 1998

27. Ballerini $P$, Blaise $A$, Busson-Le Coniat $M$, et al: HOX11L2 expression defines a clinical subtype of pediatric T-ALL associated with poor prognosis. Blood 100:991-997, 2002

28. Ferrando AA, Neuberg DS, Dodge RK, et al: Prognostic importance of TLX1 (HOX11) oncogene expression in adults with T-cell acute lymphoblastic leukaemia. Lancet 363:535-536, 2004

29. Chiaretti S, Li X, Gentleman R, et al: Gene expression profile of adult T-cell acute lymphocytic leukemia identifies distinct subsets of patients with different response to therapy and survival. Blood 103:2771-2778, 2004 